the establishment of the hypothesis of the association of motor nervenuclei; and I did not wish to compromise this by putting too great a strain upon it. The objection is that, if the thalamus be the general sensory ganglion, it should serve for the special senses as well as for common sensibility; and that, when lesion of the thalamus gives rise to hemi-anxsthesia, it ought to cause also unilaterai blindness and deafness, which it does not. Now, if bilateral association of muscles be accompanied with bilateral association of motor nerve-nuclei in the cord, and this prevent paralysis of such muscles in hemiplegia, bilateral combination of sensation ought to involve fusion of sensory nuclei. It is unnecessary to point out how complete is the combination of the vision of the two eyes : scarcely less complete is combination of sound reaching the two ears. There ought, then, to be such close association between the two optic nuclei and the two auditory nuclei as to make them practically a single nucleus for the two nerves sending fibres to the two thalami ; so that unilateral blindness or deafness, from injury to one thalamus, would be impossible. Dr. Hughlings Jackson has lately called attention to the occurrence of hemiopia with hemianæsthesia due to lesion in or near the thalamus. This appears to me to be the precise analogue of conjugate deviation of the eyes.

The function of the thalamus as the sensory ganglion will be to translate an impression arriving from the cord into a crude sensation. It is not easy to represent this in terms of cells and fibres, but it may be illustrated as follows. A finger is placed in the palm of a sleeping infant; the little hand closes gently round it. This is simply reflex. (Poor old Kentuck, in Bret Harte's story of "The Luck of Roaring Camp", would scarcely have been so excited by this simple act, had the scientific explanation of it been present to his mind.) Let the child be awake, and it will be vaguely conscious of the pressure, temperature, surface-characters, etc., of the object, but as feelings only, and without any knowledge of the external cause of its sensations. This gives roughly an idea of the office of the thalamus : it is a steppingstone between impressions and perceptions.

An example of the automatic actions effected by the thalamus and corpus striatum (the parallels of reflex actions of nerve-nuclei) will be the involuntary shrinking from a blow and the instinctive attitude of defence. The latter is none the less automatic at the moment for being "scientific" and the product of long education and training. It is not antecedently realised in consciousness; and just as the cell-andfibre apparatus in the cord concerned in standing and walking, once educated, acts automatically, so does the more complex apparatus in the sensori-motor ganglia. When a man would put up his arm, a woman might not improbably simply scream: the one and the other may be equally automatic. But we shall come to kindred subjects again.

[To be continucd.]

\section{NOTES ON WHOOPING-COUGH.}

In two cases of whooping-cough lately under my care, the phenomena preceding the spasmodic attacks were so peculiar, that I venture to think they may not he without interest to the readers of the JOURN $A \mathrm{~L}$. In the first, that of a delicate strumous-looking girl aged $\mathbf{I}$, the attacks were preceded by suffusion of the eyes and intense epigastric irritation, and could generally be checked by rubbing the epigastrium briskly. Later on in the disease, each attack finished with two distinct sneezes, instead of vomiting as before. (Trousseau mentions similar instances of this latter occurrence.) In the latter case, that of a female child aged twenty months, with a pale pasty complexion, each attack was preceiled by an irritation in the right hypochondrium, which caused her to put her hand on the spot, and exclaim that a flea was biting her. The point of interest in these cases is, that the organs irritated-in the one case, the stomach, and in the other presumably tie liver-are supplied by terminal branches of the pneumogastric nerve, for which the specific virus of the disease seems to have a special affinity. Another point of interest in the first case is the stronr similarity between the epigastric irritation and an epilcptic aura (which, moreover, is sometimes visceral), and the analogy is more striking when we remember that an epileptic attack may sometimes be checked by firmly grasping the part whence the aura proceeds. This is interesting, as bearing on the subject of the correlation of nervous disease, on which Trousseau touches in his lecture on Epilepsy. I may mention that, in this case, there was a well marked ulcer of the fronum lingua, an appearance which a recent French writer, $M$. Bouchut, considers pathognomonic : an opinion, however, with which my own experience does not accord.

\section{CLINICAL LECTURES}

\section{MOVABLE BODIES IN JOIN'TS.}

BY RICHARD BARIVELL, F.R.C.S.E., Surgeon to Charing Cross Hospital; etc.

\section{LECTURE III.}

I WILL now relate three cases of excision from the knee-join of movable bodies; in each the substance was of a diferent nature; and, as each case has its peculiarity, I will preface them separately by a cen short remarks pertinent to their special aspects, white their teacling collectively will be considered in the sequel.

The first case is that in which a bony growth was removed by direct excision after a previous vain attempt to remove it subcutaneonsly. The history is remarkable, inasmuch as the appearance of this " $\mathrm{j}$ rint mouse" immediately followed an injury; yet it formed no normal part of the joint-surface. This should be a warning against concluding, as some have done, that such bodies as make their appearance shintly after an accident must of necessity be portions broken from the ccis $t$ i. tuents of the articulation.

CASE I.-C. H., aged 43, a retired army-surgeon, came into my room on July 21 st, 1875 , and reminded me of his having consulted. me in 1872 on account of pain and difficulty on moving his right inee. He further reminded me that I, finding him in a very rheumatic con. dition, had counselled a residence abroad, and that I had mentioncd the proclivity of his then condition towards forming one or more ralse bodies in the affected knee. I remembered as he mentioned, it 7 a wing been impressed by the peculiar rough condition and the grating this synovial membrane.

He gave the following history of his condition at the above tate. In the last week of May, he tried to get into a carriage of the Netiopolitan Railway whilst it was in motion. He struck his knee sharply, and was thrown back, with some violence, upon the platform ; go: up quickly, and out of the way, fearing to be taken in charge. The $n \in \mathrm{xt}$ day he found a loose body in the knee; he had no synoritis or noin. He also said that, after this accident, he missed a lump which he previously had over the inner condyle.

I found the body easily at the time, and on several subsequent orcasions; it had no fixed residence, but, by certain movements of the limb, he could usually bring it into view. It appeared somewhat rough, hard, and about the size of a horse-bean. It could be noved into almost any part of the knee, but most easily into the subcureal sac. As a merely temporary expedient, I fastened it in that siturtion with pad and strapping. It remained stationary after this for a day or two, then slipped away, and caused a good deal of pain. Thoush he had never had a violent seizure, the annoyance was so considerable, and, being a nervous person, the dread of such an attack was so trunble. some, that he greatly desired removal of the body.

July Ioth. I got the body into place where it could be best fiven viz., above the outer condyle-and operated after Square's metho! but the body would not pass out; it slipped away, and could not be found.

July 17 th. No bad symptoms had resulted, and, prior to opering the membrane, I made an attempt to fix the body with a Glover's niedle in a properly constructed needle-holder. I found it so hard that it was impossible to introduce the point. I declined to attempt suicutan removal, fearing another failure under these conditions:

July 3 rst. II was determined to have the body ram ored : will 1 operated at the place where the body could best be fixel, riz, the outer condyle, with considerable shiftin $r$ of the skin, nit motco exclusion of air, with instruments well clennerl with carbolic acin. tite body would not come of itself from the joint, and I hal scme ti. culty, owing to its roundness and hardness, in cretting any furm s to hold it; but, after a little, I succeeded in extracting it, the elges if the wound being held close behind the body, so as to obviate any entrance of air. It was stitched, painted with collodion, and, when this wa; iny. covered with cotton-wool; the limb was then placed on an Amesining splint. Barely any swelling took place; the part remained free from nain though slight tenderness round the wound could, as might be exyected, be discovered. In fact, I regarded the patient as convalescent ; when, on the morning of the 8th August, I was sent for in great haste. found that he had, feeling some slight pain the day before, dis carded the warm applications that I, knowing his rheumatic tendency, 
hat preacuine? and used a mray of cold-I believe ice-cold-water. A complicion arose, whici hal nothing to do with the opera-

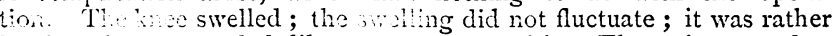
hat, ain ma rounded like an actite synoritis. The pain seemed to as the temperatme never reached Ioo, nor were there othe syrexia. The atad was, I believe, rheumatic, a condition to rincl: he was very subjou, combined with neuralgia. Convalesence wos rather tardy. In the middle of September, he went down stairs, an sictly afterwards was ont of doors. In the middle of October, he went: : Scotland, where he soon recovered the full use of the limb.

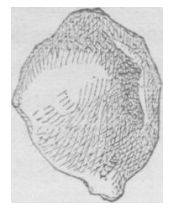

The body, nepicted of the natural size, seemed nearly as hard as the enamel of tos: it had adhering to it sme shreds of membrane, which probably wete themains of the pedicle. No broken bony or calcerous part indicated that a f.uri stalk had been smoped off by the accident above described. This body is now in the Musecin of the College of Surgeons.

Again, in my second case, wa have history of injury ; and again the body shows every appearance of being no normal part of the joint, but a row: in the immediate subjnovial tissue ; the first impulse to which we doubtless given by 2 blow, setting up first inflammatory, and then f mative, action, as described in my first lecture. The body was, I an sony to say, lost in the theatre, while I was performing another operction, by some inatrertence of one to whom it was entrusted. I liad carefully examined it; it was an oval plano-concave plate of cartinge; the concave silie was toward the joint cavity, the plain side directed towards the superficies. In climensions, its long axis was ncarly a inch, its short a.: *ither over half an inch; the thickest part, nme the edge, was as thick as a not very new shilling. One of the leng sicles of the oval hat on it a shallow gap or bay, so that the whole oniline was somewhat kidney or ear-shaped. The cartilage composits this substance liad the bluish tinge of the hyaline variety of structive: about the centre, its thinnest portion, two or three roughened and whitened spots showed that plates of calciform matter had been deposited. All one surface, and a portion of the other, had attached 0 it a fine vascular membrane; I have no doubt this was a protruted mesentery or stalk, if I may so call it, formed from synovial tissue; neithe: have I any could that this body was one of those formed in the tissue immediately underlying that structure.

CASE 1., T. Te G., aged 26 , tailor, was admitted under my care into the Charing Cross Hospital on October 15 th, 1875 , saying that he lact : cce body in his lince ('eft). When thirteen years of age, a large $:$. .e fell on his lnee; he suffered no pain or trouble at the time. II firt discovered some loose substance in the knee six years ago ; it ws then, he said, sitmated over the inner condyle of the femur, and was bi: sightly movable. For two years, it remained in this place, wil. le thought nothing of it. In 1871 , after a long walk, it sciden. was roy sick and faint. Afterwanls, the knee swelled, and he had to lay up. The same thing recured several times, though not for some months, ret he so dreaded the accident, that he was determined to have the sidsitince removed. The body's favourite resting place was at the out condyle, but it hal considerable range, though apparently not quite free novement; it fe't thet, about the size of a sixpence. ${ }^{*}$

Novemb: 3 rd. Under chloroform and carbolic acid spray, and with the slin a cood deal pulled intrard, I made a semilunar incision over the bor.....t deepened it till I fe't the synovial membrane loose below my fin I waited a few seon $1 ;$ to see that the bleeding was quite trining, and then opened the joint. The body did not come to the surface, $a$ is uscial with free ones, nor did I see it at the bottom of the wow... I passed my fing rery gently in, and felt that it had slipped a jatid, so that its in:er elge only lay under the outer lip of the wouni. I introduced a very narrow-bladed forceps, and lifted the boly into the wound. It was attached by a rather broad pedicle, and this hat to be divided before the substance could be removed. The lips of the wound were stitched with carbolised gut, dried rapidly, and thickly cuvered with collodion; the limb placed on a MacIntyre splint, with a th: $2 k$ pad of cotton-wool a swing-c.nte. No synovia flowed during the operation, and I believe no air entered the wount.

* I believe his siory as to the place whore the body first appeared to be extremely doubtful.

During the first week, he had occasional attacks of pain in the knee; these were paroxysmal, and of the sort which occur in the malady which I have termed dry or fibrinous synovitis. A blister was applied above the joint, across the front of the thigh; this relieved the pain; the temperature was never more than 99.2 .

On November I 7 th, he was allowed to get up. The limb was a little stiff from confinement.

November $23 \mathrm{rd}$. He went out walking well, with barely any stiffness. In ten days, this stiffness had quite worn off.

The next case is one of interest in many ways. Firstly, lipomatous growths are by no means uncommon, either from the peritoneum or from the tunica vaginalis; and at these places they appear as pedunculated, or as loose, bodies; but this form of growth, arising from a synovial membrane, is of extreme rarity. Secondly, the surgical value of the case is very considerable. Hydrarthrosis frequently is incurable, either by iodine injections or other means; and the knee of A. D. would probably have belonged to this class of irremediable disease if the bodies 'had not been excised. Whether all cases of very obstinate hydrarthrosis-those that resist every treatment-are dependent on the presence of undiscovered, perhaps from their situation undiscoverable, growths, is a subject for future consideration; as yet, data are not forthcoming for the solution of this question. A. D. has suffered no pain, no weakness, no swelling of the left knee, since she recovered from the operation ; but a strongly marked condition, constitutional or local, is present, which so disposes those joints to hydrarthrosis that the other knee appears to be taking on similar action.

CASE III.-Alice D., aged 26, was admitted under my care into Charing Cross Hospital, on October 16 th, with hydrarthrosis of left knee. She is a tall, stout, healthy young woman, but hysterical. In examining the joint, $\mathbf{F}$ found, just above the patella, a movable body, which seemed soft and rather large; and, on further examination, detected over the outer condyle anothersuch growth. These bodies enjoyed but a small range of motion. The knee was large, and contained a considerable quantity of fluid ; but it should be noted that both knees were fat and big; the following are the dimensions:

RIGHT.

Over patelia...........141/4 inches

Across ,

Beneath ",

...14

,"

$\begin{array}{ll}\ldots \ldots . . & 173 / 4 \\ \ldots \ldots \ldots . & 153 / 4 \\ \ldots \ldots \ldots . & 141 / 2,\end{array}$

In consequence of great press of patients for admission, I was obliged to send her out until another vacancy could be procured. The rest had been of some benefit ; on her leaving, the dimensions of the left knee were : over patella, $171 / 4$ inches; across, $15^{1 / 2}$ inches ; beneath, $14 \frac{1}{2}$ inches.

November 2nd. A. D. was readmitted. She had been suffering a good deal of pain in the knee, especially when walking, which she did with difficulty. The size was again increased : above patella, 17\%/ inches ; across, $153 / 4$ inches ; beneath, $14 \frac{1}{2}$ inches.

It will be observed that the chief swelling, as in all cases of hydrarthrosis, is above the patella, and this is the site of the loose bodies. I examined the bodies very carefully ; they appeared oval, and about the size of ordinary spectacle-glasses, and about as thick through as their short diameter, the inner one being rather the larger; they were rather soft, and enjoy no large range of motion; the inner one, which lay in front of the femur, with its lower edge about half an inch above the patella, could be pushed to the inner condyle, but not to the outer; it could be pressed under the patella, also, about an inch and a half higher than its usual seat. The outer one had a more limited range; it could be made to describe a semicircle round the outer side of the outer condyle, its end protruding a little way under the patella.

Previously to the discovery of these bodies, I had intended to treat the hydrarthrosis by injection, but now this appeared to me futile while they remained in the joint : and, with the consent of my colleagues, I determined to excise them.

November $20 t h$. She had been kept in bed since her admission for twelve days, with her leg on a pillow; the swelling of the knee had somewhat decreased. A week ago, I had the limb placed on a MacIntyre's splint, and fixed the above date for operation. Yesterday, the knee being measured, gave the following dimensions : above patella, 17 inches; across, $15 \% \frac{1}{4}$ inches ; below, 14 inches.

I operated, the patient being under chloroform, with the antiseptic precautions, by making a slightly curved longitudinal incision above and on the inner margin of the external condyle; this I gradually deepened, and, waiting till the slight hæmorrhage had nearly ceased, I opened the synovial membrane. After a little manœuvring, the outer body sprang out, and hung by a small stalk; this was cut through. I found it impossible to get the inner body to protrude. I therefore wiped all blood from my finger; and, after subjecting it for a while to the spray, intro- 
duced it carefully into the joint, easily found the body, but could not draw it further inward. I followed it with my finger across the joint to the inner condyle, and tried to detach it, but was foiled. I now seized it in a pair of forceps, drew it as far as possible out of the wound, and, with a scalpel introduced as far as was safe, separated it, leaving a very small part of the body behind, in the hope that it would shrivel away. A good deal of synovia flowed during the operation. The bodies were lipomatous, and, while warm, looked, except that they were more pear-shaped, exactly like native oysters without the beard; the colour and size were exact imitations while they were warm, but, on getting coid, the translucent parts changed in appearance, and then became still more white and opaque on being put into spirit.

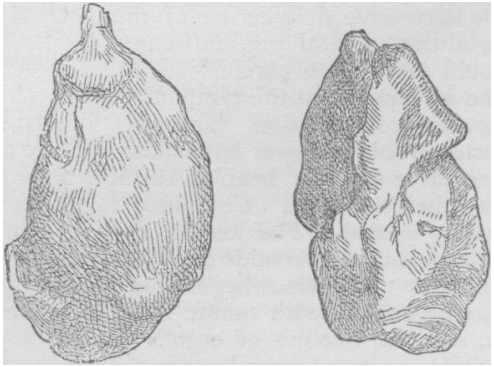

Representations (natural size) of the bodies removed. The onc on the right is that which grew from the inner condyle; the left, that which grew from
the outer.

December 2nd. She had had occasional attacks of pain, but not severe. The temperature varied from 98.4 to 100 ; pulse quite normal. I undid the bandages, removed the cotton-wool and the collodion covering, which was rather loose. The wound had not healed. Between its lips was a clot of blood, looking as purple and as fresh as though it had only just been effused. The knee appeared a good deal smaller than it was before operation; she had some slight tenderness over the whole joint, but chiefly at a place over the inner condyle, which she, unprompted, described as "the place where you removed the larger body".

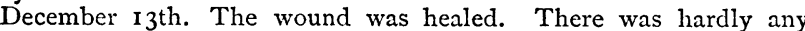
tenderness, probably no real tenderness; but it was difficult to juclge. She had rather frequent and prolonged fits of hysterical weeping. I removed the splint, and moved the leg through about thirty degrees, quite smoothly and without pain.

December 23rd. She went out walking, well and free from pain. The size of the knee was: above patella, I 5 inches; across, 14 $1 / 2$ inches; below, I $31 / 2$ inches.

March 8th. The patient not having presented herself for examination as ordered, I found her at her residence. The knee was perfectly well, having the same dimensions as above. The part of the inner loose body which I had been obliged to leave attached could not be detected. The other knee showed some swelling and tendency to hy drarthrosis. She states that she never has any pain nor sense of weakness in the left knee, but occasional pain in the other.

In considering the result of these cases and the choice of operation, it is to be observed that the subcutaneous method must have failed in the two last, the bodies being, all three of them, attached to the synovial membrane of the joint. The fact of their having marked limits to their mobility-much wider in the case of de $G$. than in that of Alice D.-had apprised me of this condition. In the first case, although the body was evidently perfectly free, and although I made a quite suff. ciently wide opening in the capsule of the joint, it was impossible to extrude the substance; this I attribute to its hardness and to its rounded shape. These observations bear out the remarks in my second lecture, viz., that the subcutaneous method must in certain cases fail, and that such mode of operation should be avoided when limited mobility indicates persistence of the peduncle; further, that such method will occasionally fail, ever when larger mobility exists, and gives assurance of an entirely free substance.

We now come to those precautions which render extraction of such bodies by the direct method a very safe proceeding. Numbers of such operations have been performed without antiseptics and without any ill consequences; the secret of such success lying in exclusion of air from the wound. This essential must in great measure depend on the assistant who closes the deeper parts as the body moves outwards, and as it escapes, the skin. Then, if the incision be large, it must be stitched with wire or catgut, covered with collodion, and, when that is dry, with well cleansed cotton-wool, the limb being bandaged and placed on a splint.
Such is the method which was followed with C. H. with complete success. * My assistant was very careful and skilful in carrying out my directions; but I saw, then, that had the extraction presented greater difficulties than it actually did, entire exclusion of air might have been impossible. In my next cases, therefore, I operated under the carbolic spray. In the case of T. de G., I had to pass forceps into the joint, and then divide a broad pedicle, yet no bad symptom followed. In the case of Alice D., still greater liberties were taken with the joint. I passed my finger right across it from the outer condyle, beneath the rectus tendon to the inner ; divided two pedicles, one being broad and thick; moreover, a quantity of synovia flowed out during the operation. No bad symptom, no pyrexia followed; hence I hold that these results justify what I said at the conclusion of my previous lecture, that the antiseptic method renders this operation absolutely safe; also, that this great improvement in surgery must completely change the relative value and safety of all such operations as compared with subcutaneous methods.

\section{REMARKS ON ENTERIC FEVER.}

BY JOHN RICHARD WARDELL, M.D., F.R.C.P., Senior Physician to the Tunbridge Wells Infirmary.

[Concluded from page 379 of last number.]

IN the case of another lady, which occurred some time ago, which passed on to a fatal termination, and in which I took a sad and mournful interest, I could not, after much subsequent and painful investigation, discover the ordinarily recognised cause of the disease. Without entering into the details of the facts, I have always been driven to the conclusion that a repetition of family bereavements and the fatigue and watching during an illness, produced so much depression and exhaustion in the system as to develope in the organism those conditions which end in the more ostensible phenomena of the distemper. Previously to that time, I had always held to the doctrine of an imperative necessity for the specific poison being imported into the body. My subsequent experience, from certain seeming illustrations and circumstances, has gone to confirm the belief that, under special and peculiar conditions, enteric fever can become instituted in the system without any external agencies other than such common causes as give rise to that lowered tone of vitality which favours the springing up within itself of the morbid phenomena in question. In my early life, and prior to the time when the now recognised types of continued fever were known as they now are known, I can call to mind sporadic cases which, from time to time, occurred in an agricultural and very sparsely populated part of the country, where the theory of a specific poison being superadded to other elements in the causation is hardly in any wise tenable. And I feel persuaded that the correct solution of these still contested and debatable questions relative to the etiology of enteric fever, mainly lies not amongst the physicians and practitioners in the metropolitan cities and large towns, but rather with those whose powers of observation are confined to small and separated communities, such as in villages and rural districts. I have often thought that if this subject, and kindred inquiries, were to be broadly taken up by the rural members of the British Medical Association, such an amount of information and facts would be elicited as to finally settle many points still uncertain and held in disputation. Such etiological researches in urban centres and dense populations are liable to be vitiated in innumerable ways. Doubtless, enteric fever can, as the rule, be traced to bad drainage, polluted water, and, in more limited degree, to contagion; but I also now firmly believe, as asserted above, that it may occasionally with trutb be referred to an autogenetic origin. In medicine, as in theology and politics, it is now found there is need, in many hitherto accepted propositions, of broader survey and greater liberalism of thought; and that many dogmas and arbitrarily demarcated definitions must be subjected to the test of a sounder reasoning and deeper scrutiny.

Since the foregoing paragraph was written, I happened to meet my friend Dr. Baylis, the able and indefatigable Sanitary Inspector for West Kent; and I asked his opinion relative to this my belief in the autogenetic doctrine. This gentleman assured me he is becoming more and more a convert to this theory. He told me he has latterly been in various parts of the county to investigate into the cause of several sporadic cases of enteric fever, some of which were in peculiarly isolated positions; and, after much labour and inquiry, he could only arrive at the conclusion that all the arguments and all the circumstances excluded the notion of an imported or resuscitated specific

* The subsequent complication had nothing to do with an open or suppurating condition of the wound, but was due to rheumatic constitution and other causes. 